Boise State University

ScholarWorks

Psychological Sciences Faculty Publications and

Presentations

Department of Psychological Science

$1-1-2011$

\title{
Processes of Sexual Orientation Questioning Among Heterosexual Women
}

Elizabeth M. Morgan

Boise State University

Elisabeth Morgan Thompson

University of Arizona 


\title{
Processes of Sexual Orientation Questioning Among Heterosexual Women
}

\author{
Elizabeth M. Morgan \\ Boise State University
}

\author{
Elisabeth Morgan Thompson \\ University of Arizona
}

\begin{abstract}
Because very little is known about heterosexual identity development, this study assesses and describes sexual orientation questioning processes of heterosexual-identified women, and offers a comparison of these processes with those employed by their sexual-minority counterparts. Participants included 333 female college students (ages 18-23; $M=19.2$ ). Two-hundred and twenty-eight participants primarily identified as "exclusively straight/heterosexual”; 105 participants indicated a sexual-minority identity. Sixty-seven percent of exclusively heterosexual respondents $(n=154)$ indicated having thought about and/or questioned their sexual orientation. The processes by which heterosexual participants described questioning their sexual orientation were coded for the presence of five emergent categories using an inductive thematic coding methodology. These five categories included: unelaborated questioning (19\%), other-sex experiences (16\%), exposure to sexual minorities (26\%), assessment of same-sex attraction (48\%), and evaluations of same-sex behavior (26\%). Several unifying and differentiating themes emerged between sexual orientation groups. Results from this study suggest that contemporary young women's heterosexuality is not necessarily an unexamined identity; indeed, the large majority of young women in this sample were deliberately identifying as heterosexual after contemplating alternative possibilities.
\end{abstract}

In the amplitude of research exploring female sexual development, heterosexual identity development often goes unexamined and ignored. Instead, research on heterosexual women's sexual development has focused primarily on behavioral or attitudinal outcomes, without attention to a more multifaceted understanding of identity. In most cases, these studies neglect to probe for information regarding processes of sexual identity development and personal sexual histories, often rendering heterosexuality invisible. When (hetero)sexual behavior is examined, it is surrounded by discussions of risk, especially in a "hook-up" culture, with a focus on casual sex, contraception, sexually transmitted infections/diseases, substance (ab)use, and threat of sexual assault (e.g., Hughes, Johnson, \& Wilsnack, 2001; Jackson, 2005; Lambert, Kahn, \& Apple, 2003; Long, Ullman, Long, Mason, \& Starzynski, 2007; Reddy \& Dunne, 2007; Roberts, Auinger, \& Klein, 2006). When not interested in sexual behavior per se, research on women's (hetero)sexual development tends to focus on gender instead; for example, the negotiation of and attitudes toward limiting gender roles, gendered heterosexual scripts, sexual double standards, and the socialization of femininity (e.g., Jackson \& Cram, 2003; Kim, Sorsoli, Collins, Zylbergold, Schooler, \& Tolman, 2007; Morgan \& Zurbriggen, 2007; Striepe \& Tolman, 2003). As a result of these patterns of study, heterosexual individuals are not frequently asked to describe how they established their sexual identity (for and exception see Eliason, 1995). The present study seeks a better understanding of young women's heterosexual identity development through an exploratory examination of the presence and processes of sexual orientation questioning among a college population.

In comparison to the extant research on sexual-minority groups' processes of questioning, heterosexual identity development has received little empirical attention (Worthington, Savoy, Dillon, \& Vernaglia, 2002). Indeed, when sexual identity researchers have commented on heterosexual identity, it has been noted that most heterosexual individuals do not think about their sexual identity and heterosexuality is conceptualized as an unmarked identity (Diamond, 2008b). The invisibility of questioning processes for heterosexual individuals may be explained in large part through compulsory heterosexuality. Within the context of compulsory heterosexuality, a heterosexual identity is viewed as the only option and is conceptualized narrowly as both inherent and uniform, rendering it a "silent" identity (Kitzinger \& Wilkinson, 1993; Konik \& Stewart, 2004). While compulsory heterosexuality affects both men and women, some feminist scholars have noted differential and unequal material conditions that render heterosexuality necessary for women's economic and social sustainment (Rich, 1980; Kitzinger \& Wilkinson). 
Two key components of compulsory heterosexuality are hegemonic masculinity (see Connell, 2006) and hegemonic femininity. According to Tolman (2006), among other things, "hegemonic femininity demands that (good) [heterosexual] girls not have sexual agency, that is, a sense of themselves as sexual beings entitled to feel and act on their own feelings" (p. 76). That is, sexual and social passivity in relationships with men are part and parcel to a heterosexual identity and the "regulation of divers[ity in] women's sexuality" (Tolman, p. 74). Research examining the role of hegemonic femininity in adolescent girls' sexual health and agency has found a negative association between feminine ideology and both sexual self-efficacy and healthy sexual behaviors (Impett, Schooler \& Tolman, 2006). In another study, girls who reported less self-objectification also evidenced more comfort talking about sexuality and engaged in greater sexual experimentation (Hirschman, Impett \& Schooler, 2006). Because the prevailing social norms guiding young women's sexuality conceive female (hetero)sexuality as passive, devoid of desire, and subordinate to male needs, it is natural that conceptualizations of young women's sexual identity development often assume that the heterosexual identity is similarly constructed through passive and unexamined processes.

The theoretical and empirical work examining women's sexual-minority identity development provides a useful starting point for considering sexual identity development, though the processes are likely quite different for heterosexually-identified young women. Contributions from a number of researchers (Cass, 1979; Cass, 1984; Fassinger, 2000; Fassinger \& Miller, 1996; Herdt, 1992; Savin-Williams, 1995; Troiden, 1989) have shaped the study of sexual identity, focusing chiefly on developmental models aimed at understanding the emergence and adoption of a sexual-minority identity. With the more recent expansion of identity categories, scholars have suggested developmental trajectories or sexual "lifeways" to be a better descriptor of the diverse processes and multiple pathways that lead to a sexual-minority identity (Hostetler \& Herdt, 1998; Savin-Williams, 2005; SavinWilliams \& Diamond, 2000). All of these models and trajectories incorporate some form of coming to awareness of one's sexual orientation or exploration of one's sexuality (see McCarn \& Fassinger, 1996 and Fassigner \& Miller, 1996 for reviews). Within this research, sexual questioning processes can be defined as, "struggles over identifying and authenticating subjective experiences of same-sex and other-sex attractions" (Diamond, 2005b, p. 12). This includes, but is not limited to critical interrogations of "subjective experiences of sexual arousal, pleasure, disgust, disinterest, affection, infatuation, and love, as well as the social meaning of these experiences" (Diamond, p. 10). Not surprisingly, research indicates that sexual-minority individuals have often described their sexual identities as salient and involving an effortful process and have even indicated higher exploration and commitment in other domains of identity than heterosexually-identified young adults (Konik \& Stewart, 2004). As such, research on sexual-minority identity development is helpful in providing a framework from which to begin an investigation into heterosexual identity development, but cannot be relied upon for understanding the differences between sexualminority and heterosexual individuals' developmental trajectories.

Research has evidenced unique experiences specific to women's sexual identity development that help inform possible developmental trajectories for heterosexual women. Several studies have revealed heightened fluidity in young women's sexual identity (Diamond 2005a, 2008a, 2008b) as well as diversity within women’s sexual identity labels, including a significant number of young women who distinguish themselves as "mostly straight" (Thompson \& Morgan, 2008). Also important is the ample evidence that young women's sexual orientation indicators (e.g., behavior, attraction, fantasies) do not always match up perfectly with the identity label they have chosen (Amestoy, 2001; Remafedi, Resnick, Blum, \& Harris, 1992; Thompson \& Morgan), highlighting the fact that many heterosexual women may have histories of same-sex behavior and that women often come to a sexual-minority identity after a significant history of heterosexual behavior and identification (Chapman \& Brannock, 1987; Kinnish, Strassberg, \& Turner, 2005; Kitzinger \& Wilkinson, 1995). Diamond's (2008a, 2008b) longitudinal study furthermore revealed that the majority of women shifted their identity label at least once and that some women who previously identified with sexual-minority labels did in fact adopt a heterosexual identity at various points throughout the ten years of the study. This body of research is especially relevant to the present study, because it highlights the fact that a heterosexual identity does not consistently reflect a stable, initial, or uniform sexual attraction, behavior or identification experience. However, it is important to note that this research has mainly been conducted with populations identifying with a sexual-minority label at some point and is not necessarily applicable to women who have consistently identified as exclusively heterosexual.

Despite indications that women's heterosexual identity development may indeed be a complex and multifaceted process, research on women's heterosexual identity development is scant. Worthington et al. (2002) proposed a general model that helps elucidate questioning as a part of a heterosexual identity during its phase of active 
exploration. Worthington et al. suggest that most heterosexuals begin with a commitment to a heterosexual identity without a conscious exploration of that self-labeling, and because of compulsory heterosexuality many heterosexuals rarely move out of this phase. However, for some, active cognitive or behavioral exploration of one's heterosexual identity can take place with symbolic or real other-sex and same-sex experimentation while reserving "the privileged status associated with identification as heterosexual” (Worthington et al., p. 517). This model importantly places emphasis on both the individual and social components of a heterosexual identity, such that as the individual seeks to understand his/her emerging heterosexual desires, s/he also discovers the sociocultural meanings attached to being a member of a distinct social group.

In spite of its theoretical potential, this model has not been empirically validated and its application to women's heterosexual identity development remains to be seen. A mere handful of studies have addressed heterosexual identity in women (e.g., Boratav, 2006; Eliason, 1995), yielding mixed results. In most studies, sexual identity questioning is left unreported due to underdeveloped methodologies regarding "questioning"; that is, information about "questioning" is more of a by-product of the data collected rather than a result of specific inquiries. For example, in Boratav's (2006) questionnaire study of Turkish students, ninety-four percent of heterosexual informants expected their sexual identities to always remain the same, highlighting an "unmarked," unquestioned identity. In Eliason's (1995) examination of heterosexual college students' essays, she found that almost one-quarter of her heterosexual women participants (compared to more than 1/3 of men) had never thought about, much less questioned, their sexual identity. However, Eliason also found that heterosexual women's identities were more likely to be in moratorium (exploration with no commitment) and less likely to be foreclosed (commitment with no exploration) than heterosexual men's identities, suggesting they were perhaps prone to exploratory sexual experiences and questioning. Striepe and Tolman's (2003) interviews with adolescents also revealed purposeful examinations of heterosexuality as a result of not conforming to prescribed heterosexual gender ideologies for both girls and boys.

Due to the paucity of empirical research examining heterosexual identity development, heterosexual women's questioning processes are in need of further investigation and clarification. With same-sex desire becoming increasingly culturally normative (Savin-Williams, 2005) and increased insight into the identity processes of sexualminority women, it would not be surprising if more heterosexual women were questioning their identity than the theoretical models predict. The present study offers an exploratory examination of sexual orientation questioning processes among heterosexually-identified young women to help generate a preliminary understanding of sexual identity development among this population.

\section{Present Study}

We had several goals in conducting this research. Given that research has not previously examined sexual orientation questioning among heterosexual women, our first goal was to assess the frequency with which heterosexual college women actually question their sexual orientation. Because a prior study on heterosexual men's questioning revealed that about half of these participants had questioned their sexual orientation (Morgan, Steiner, \& Thompson, in press) and because restrictions on women's same-sex activities in the context of a heterosexual identity are somewhat more relaxed (e.g., Diamond, 2002, 2005c), we anticipated that more than half of female participants would indicate having questioned their sexual orientation.

To ascertain differences between the heterosexual questioning population and the non-questioning population, our second goal was to compare questioning and non-questioning heterosexual women on quantitative measures of feminine gender ideology, sexual identity commitment and exploration, other-sex and same-sex sexual experience, and attitudes towards lesbian/gay/bisexual individuals. These measures were chosen because they represent relevant aspects of sexual identity (Worthington et al., 2002), including personal values, attitudes and behaviors, as well as attitudes towards other groups (i.e., lesbian/gay/bisexual individuals). On these measures, we anticipated some differences to emerge between the groups, but also similarities, as both groups primarily identify as heterosexual. We hypothesized that questioning women would indicate less endorsement of statements reflective of feminine gender ideology, greater sexual identity exploration and uncertainty, less sexual identity commitment and synthesis/integration, and more positive attitudes towards lesbian/gay/bisexual individuals. We also expected similar levels of other-sex behavior and somewhat higher levels of same-sex behavior among questioning women than among non-questioning women. 
Following the comparative quantitative analyses, our third goal was to qualitatively examine questioning women's narratives to describe sexual orientation questioning among this population, including ascertaining the ways in which questioning has occurred, what it looked like, and the impetuses for the questioning (i.e., "questioning processes"). A qualitative methodology was chosen to facilitate an inductive approach to this research question, due to the lack of previous research on this topic. Because questioning is paramount to both heterosexual and sexualminority identity development models, the present study will also use sexual-minority women's narratives regarding sexual orientation questioning as a comparison point for understanding heterosexual questioning processes.

\section{Method}

\section{Participants}

The initial sample of participants consisted of 575 undergraduate college students; however, only female-identified participants with complete responses were analyzed for this study $(n=333)$. Participants were mostly emerging adults (ages ranged from 18 to 23; $M=19.2$ ). Participants' racial backgrounds included European-American/White ( $n=229 ; 69 \%$ ), Asian-American/Pacific Islander ( $n=48 ; 14 \%)$, Mexican-American/Latina $(n=32 ; 10 \%)$, Bi/Multiracial $(n=15 ; 4 \%)$ and unspecified $(n=9 ; 3 \%)$. Participants included 128 first-year students, 122 sophomores, 43 juniors, and 40 seniors.

In response to the question "When you think about your sexual orientation, what term do you most identify with?," 228 women (68\%) indicated "exclusively straight/heterosexual." The remaining women $(n=105)$ were placed in the "sexual-minority" group for comparative analyses, and included women who primarily identified as "mostly straight with some bisexual tendencies" ( $n=73)$, "bisexual” $(n=21)$, "mostly gay/lesbian” $(n=4)$, and "exclusively gay/lesbian" $(n=7)$. "Mostly straight” identifying women were included in the sexual-minority group because in previous studies this group distinguished itself from exclusively heterosexual participants regarding same-sex attraction and experiences (Thompson \& Morgan, 2008).

\section{Procedure}

Procedures were the same as those used in a similar study on the questioning processes of heterosexual men (Morgan, et al., in press). All participants were college students enrolled in a lower division psychology course at a public university in northern California and participated to fulfill a course requirement. Participants were given information about the content of the questionnaire and elected to participate in the study through an online educational experiment system. Participants were instructed to complete the questionnaire via a secure, online survey website (http://www.surveymonkey.com). The procedure, including consent, debriefing, and credit allocation, took place online. After giving consent, participants completed a demographics section and two openended questions about sexual orientation development. Following these questions, participants completed several additional measures of sexual attitudes and experiences, some of which were not analyzed in this study. The questionnaire took approximately 90 minutes to complete.

\section{Measures}

In addition to a demographic questionnaire, participants completed the following measures: sexual orientation questioning, the Adolescent Femininity Ideology Scale (AFIS), the Lesbian Gay and Bisexual Knowledge and Attitudes Scale for Heterosexuals (LGB-KASH), a measure of other-sex and same-sex sexual behavior, and the Measure of Sexual Identity Exploration and Commitment (MoSIEC).

Sexual orientation questioning. Narrative responses from two open-ended questions were used to assess sexual orientation questioning. The first question inquired, "Have you thought much about and/or questioned your sexual orientation? If yes, when do you first remember thinking about your sexual orientation? If no, why do you think you have never thought about this?” The second question asked, "What has been important in developing your sexual orientation? Please be as specific as possible." Participants were provided with unlimited text space to answer these questions. 
Adolescent Femininity Ideology Scale (AFIS). Participants completed the 20-item AFIS (Tolman \& Porche, 2000), which assesses personal endorsement of items that relate to traditional feminine ideologies (e.g., "I express my opinions only if I can think of a nice way of doing it" and "I think that a girl has to be thin to feel beautiful"). Responses were measured on a seven point scale ( $1=$ strongly disagree, $4=$ neither agree nor disagree, 7 = strongly agree). Cronbach's alpha for this measure was .80 .

LGB-KASH. Participants completed the 34-item LGB-KASH (Worthington, Dillon, and Becker-Schutte, 2005). This scale assesses personal attitudes towards lesbian, gay, and bisexual individuals, written from a heterosexual perspective. Four of the five subscales were analyzed for this study: Endorsement of Hate Crimes (e.g., "It is important for me to avoid LGB individuals."), Internalized Affirmativeness (e.g., "I would display a symbol of gay pride (pink triangle, rainbow, etc.) to show my support of the LGB community.”), Knowledge of LGB History and Community (e.g., "I am knowledgeable about the history and mission of the PFLAG organization.”), and Support for LGB Civil Rights (e.g., "Health benefits should be available equally to same-sex partners as to any other couple.”). Responses were measured on a seven point scale (1= strongly disagree, $4=$ neither agree nor disagree, $7=$ strongly agree). Cronbach’s alpha for each subscale ranged from .81 to .92.

Other-sex and same-sex sexual behavior. Other-sex and same-sex sexual behavior was assessed through two sets of questions. The first set of 22 questions assessed the frequency with which participants engaged in a variety of romantic/sexual activities (e.g., hand holding, light kissing, receiving and performing oral sex) with the other-sex and the same-sex. Responses for the frequency of occurrence items were given on a five-point Likert-type scale $(1=$ never, 3 = three to five times, $5=$ ten or more times). The second set of 22 questions assessed the number of othersex and same-sex partners for the same sets of romantic/sexual activities. Responses for the number of partner(s) items were also given on a five-point Likert-type scale ( $1=$ no one, $3=$ three to five people, $5=$ ten or more people). Four scores were calculated by averaging responses for each set of questions, which yielded a "Frequency of Othersex Behavior" and "Frequency of Same-sex Behavior" score potentially ranging from 1 (no experience) to 5 (highest possible frequency of other-sex or same-sex experience) and a "Number of Other-sex Partners" as well as a "Number of Same-sex Partners" score potentially ranging from 1 (no partners) to 5 (highest number of other-sex or same-sex partners). Cronbach's alpha for each subscale ranged from .91 to .96.

MoSIEC. The Measure of Sexual Identity Exploration and Commitment, developed by Worthington, Navarro, Savoy and Hampton (2008) applies Marcia's (1966) identity framework to sexual identity. This 22-item scale has four distinct factors which are common across all sexual orientation identities: exploration, uncertainty, commitment, and synthesis/integration. Sample items included, "I am actively trying to learn more about my own sexual needs" (exploration; 8 items), "I sometimes feel uncertain about my sexual orientation" (uncertainty; 3 items), "I have a clear sense of the types of sexual activities I prefer" (sexual orientation commitment; 6 items), and "My understanding of my sexual needs coincides with my overall sense of sexual self" (synthesis/integration; 6 items). Response options ranged from one (strongly disagree) to five (strongly agree), with a midpoint of three (neither disagree nor agree). Cronbach’s alpha for each subscale ranged from .77 to .86.

\section{Analysis and Preliminary Coding}

Preliminary analyses classified heterosexual women's open-ended responses regarding sexual orientation questioning into two categories: questioning and non-questioning. Questioning narratives included those in which the participant explicitly noted or implicitly described that she had thought about and/or questioned her sexual orientation in the past, was currently questioning her sexual orientation, or had considered future changes to her sexual identity. All responses were coded by two undergraduate research assistants with adequate reliability; Cohen’s Kappa was .91 and percent agreement was 96 percent. The nine discrepancies were the result of ambiguous participant narratives; these were resolved in discussions between the first author and the research assistants. When using this classification system, results indicated that 154 (67.5\%) of "exclusively straight" women had or were currently questioning their sexual orientation and 74 (32.5\%) of "exclusively straight" women had not questioned their sexual orientation.

In recognition that "thinking about” one's sexual orientation can be different than "questioning” one's sexual orientation, narratives were carefully reviewed to ascertain if responses should be separately categorized based on this distinction. However, participants who specifically reported "thinking about" their sexual orientation ( $n=57$, $37 \%)$ provided similar narratives, examples, and explanations as those who specifically noted "questioning" ( $n=97$, 
63\%) their sexual orientation. For example, one participant wrote, "Yes, I have thought about my sexual orientation from a very early age-maybe eight or so. I wasn't sure if I liked guys or girls.” Furthermore, these two groups of participants (those who reported thinking about versus questioning their sexual orientation) did not differ on any of our quantitative measures (e.g., AFIS, LGB-KASH, MoSIEC, or sexual behavior scales, all $p$ 's > .10). Thus, all participants who indicated either of these processes were combined into one coding category, which for convenience we labeled "questioning." Non-questioning narratives were those in which participants explicitly indicated or implicitly described having never questioned their sexual orientation.

We also examined the 105 "sexual-minority" women's narratives; all but two of these participants indicated that they had questioned or were currently questioning their sexual orientation. Thus, the preliminary coding process yielded three groups that were used for further analyses: heterosexual questioning women (HQ; $n=154)$, heterosexual non-questioning women (HNQ; $n=74)$, and sexual-minority women $(n=105)$. A one-way ANOVA revealed significant age differences between the three groups, $F(2,330)=4.16 p=.02)$, such that the sexualminority group was significantly older $(M=19.43)$ than the heterosexual non-questioning group $(M=18.95)$; there was no difference between the heterosexual questioning group $(M=19.13)$ and either of the other two groups. Chisquare analyses revealed no significant differences among these three groups regarding the racial/ethnic background $(p>.10)$.

Further analyses included a qualitative review of the questioning women's narratives, which was conducted using an inductive thematic analysis approach (Braun \& Clarke, 2006) because previous research has not described sexual orientation questioning among this population. The first step in the coding process involved reading narratives closely for emergent themes in participant's descriptions of their questioning processes. Once the themes were categorized, all narratives were reviewed for the presence and absence of each category; these categories are described with an example narrative in Table 1. Because multiple themes occasionally emerged in the same narrative, responses could receive a "present" code for more than one theme (except for "unelaborated," which was mutually exclusive from the other four themes). All narratives received a "present" code for at least one category. Narrative responses were coded by two undergraduate research assistants with adequate reliability; Cohen's Kappa ranged from .80-.96 and percent agreement was at least 89 percent on all coding categories (See Table 1). Discrepant narratives were typically the result of lack of attention to an aspect of the narrative or a vague statement and were resolved through discussions between the first author and the research assistants. Excerpts were selected for presentation as exemplars of the thematic patterns observed across the responses.

\section{Results}

\section{Comparisons between HQ and HNQ women}

To better understand the potential differences between heterosexual-identified women who report having questioned their sexual orientation and those who reported having never questioned their sexual orientations, we contrasted HQ women's responses with those of HNQ women regarding quantitative measures of feminine gender ideology, attitudes towards LGB individuals, other-sex and same-sex behavioral experiences, and sexual identity development. Table 2 presents means, standard deviations and t-tests assessing differences between HQ and HNQ women for each of these variables.

Regarding feminine gender ideology (as measured by the AFIS), no differences emerged between HQ and HNQ women. Both HQ and HNQ women's scores were similarly below the midpoint of the scale, suggesting that both groups had equally low endorsement of statements representing feminine gender ideology. Differences between HQ and HNQ participants did emerge for all four subscales of the knowledge and attitudes of LGB individuals scale with moderate to large effect sizes. As expected, HQ women indicated greater internalized affirmativeness, support of LGB civil rights, and knowledge of LGB history and community than HNQ women. HQ women also indicated less endorsement of LGB hate crimes than HNQ women, though both groups presented averages well below the midpoint of the scale.

Regarding sexual behavior, there were no differences as expected between HQ and HNQ women's frequency of other-sex sexual experiences or number of other-sex partners. However, there were significant differences between the groups' same-sex behavior. As predicted, HQ women reported higher frequency of engagement with same-sex behavior and more same-sex partners than HNQ women. However, it is important to note that these were moderate 
to small effect sizes and that both HQ and HNQ women did report same-sex sexual experiences. For example, $60 \%$ of HQ women indicated they had engaged in light same-sex kissing while $42 \%$ of HNQ women reported this behavior. Forty-three percent of HQ indicated having "made out" (close body contact with hugging and prolonged kissing) with another female as opposed to $17 \%$ of HNQ women. Also, 4\% of HQ women indicated having given oral sex to another woman while just over $1 \%$ of HNQ women reported this behavior.

Lastly, groups were assessed regarding sexual identity variables. Counter to our hypothesis, HQ and HNQ women did not differ on the commitment subscale. However, HQ women did have lower scores than the HNQ women on the synthesis/integration subscale. As expected, HQ women indicated higher levels of uncertainty and exploration than HNQ women.

\section{Qualitative Analyses of Heterosexual Questioning Women's Narratives}

To better understand what sexual identity questioning looks like for heterosexual women, their narratives were analyzed for prominent themes. Below is a discussion of the five discrete themes that emerged and how they represent the various forms of sexual identity questioning and exploration as described by the young women in this study. These five categories included: unelaborated questioning (19\%), other-sex experiences (16\%), exposure to sexual minorities (26\%), assessment of same-sex attraction (48\%), and evaluations of same-sex behavior (26\%).

Unelaborated questioning. Narratives in this category typically included a statement that the participant had questioned her sexual orientation and an indication of how old she was when she did so. For example, one participant reported, "I've questioned my orientation a million times, and still do. The first time I did I was about 12." Another participant explained, "When I was an adolescent, I questioned my sexuality. I had always thought of myself as heterosexual, but there was a brief period of time that I questioned that. I am now secure in my heterosexuality.” Other narratives in this category included slightly more information regarding the participants' perspectives of their questioning process, but were not appropriate for any of the other categories. For example, one participant explained, "I suppose I've thought about it. I believe (or like to hope) that everyone is bisexual and that you don't choose whom you're involved with by a single characteristic (like gender, race, religious beliefs, etc.) and that you fall for or are interested in the person.”

Other-sex influences. This category included descriptions of questioning that involved concluding a heterosexual identity following an assessment of their relationships with men as positive, as well as questioning following difficulties entering into or in relationships with boys. Most notable in this category were the participants who described not feeling ready or comfortable dating or being sexual with boys during middle school or high school, but had friends who were dating. As a result, the participants described questioning their sexual orientations and/or using "being gay" as an excuse for not dating. For example, one participant explained,

"Yes I have thought about my sexual orientation. I think that the first time I thought about my sexual orientation was somewhere around middle school. All of my friends began to experiment with boys, and I didn't really seem to care for that. I felt pressured to mess around with boys, and finally broke under it. I identify myself as heterosexual, and think that this experience of being forced into it might have contributed to that."

Other participants described that their questioning was a result of boys not being interested in them: "There was a point where I wasn't dating anyone for a long time and I wondered if I was a lesbian.” Several participants who had dated boys, but not with great success, explained that these negative relationship experiences prompted them to question their sexual orientation. For example, one participant explained, "I questioned it briefly when I was 16 because so far all my relationships with boys had been huge failures, and I've always thought that there are more attractive girls in the world than guys.”

Exposure to sexual minorities. This category included narratives in which the participant noted that an aspect of her social context, generally relationships with sexual-minority individuals, prompted her to question her own sexual orientation. For many participants, this included generally coming into contact with GLB communities or individuals in high school or college. For example, one participant described that she generally socialized with a "queer" crowd of students. She explained, "The issue of my sexual orientation probably arose first in 9th grade when I became involved with the gay-straight alliance at my school. As a result of my experiences I often question 
my sexual orientation and wonder if I am attracted to women.” Participants also described college as an important social context. "I never really questioned my sexual orientation for much of my life, but have a little since coming to college. Not so much because I feel confused but because there are so many people here who are open with their sexuality, which leads me to consider my own.”

Other participants described situations in which contact with sexual-minority friends prompted questioning. One participant explained, "I am straight, but about 2 years ago, one of my best friends told me he was gay. I wondered how he figured it out and started questioning why I was not attracted to girls. This actually made me notice that sometimes I thought girls were very attractive, but I had no desire to act on it.” Other participants described questioning their sexual orientation when someone else asked them if they were gay. For example, a participant relayed, "Yes, when this boy, who used to be a friend, asked me if I was gay. I had never felt that way, but I started wondering why he thought that." Lastly, participants reported questioning their sexual orientation when sexualminority friends disclosed sexual interest in them. For example, one participant explained, "Yes, I have questioned my sexual orientation. My senior year of high school a good friend of mine who is a lesbian began taking a lot of interest in me. I felt so flattered and really believed for a while that I liked her back. She was the first and only girl I've ever had a real crush on though I am attracted to many.”

Assessment of same-sex attraction. Many participants noted that questioning included an assessment of their same sex-attraction. As a result, many explained that they find women attractive, but not in a sexual manner. For example, one participant explained, "I do think a lot of my girl friends are beautiful but I don't find them sexually attractive." Other participants did describe a sexual attraction to women, but noted that they were not interested in romantic or sexual relationships with women. One participant explained, "While I find women's bodies very attractive, I cannot see myself in a serious emotional, romantic involvement with a woman. I often find women more visually appealing than men, but to the touch (which is more important to me sexually), I enjoy men's bodies more.” Participants also often described their attraction towards women, and then compared it to their feelings towards men. For example one participant explained, "Sometimes I think women are very beautiful more so than men, but there's a difference, women ARE beautiful, men are handsome, and when all is said and done I want a handsome man to sweep me off my feet." Ultimately, while participants frequently noted some form of appreciation for women's appearance or sexual attraction to women, their greater interest in men or lack of interest in pursuing women for relationships enabled a continued identification as heterosexual.

Evaluations of same-sex behavior. The same-sex behaviors that instigated or provided a basis for sexual orientation questioning generally involved kissing friends when intoxicated and in the presence of others, including men. For example, one participant explained that:

“I have questioned my sexuality briefly, but it hasn't ever changed. I'm straight, but sometime senior year, all of my girlfriends and I went through an experimentation phase and we all made out with each other every time we drank. I have since kissed many girls, but I don't think it means that I'm gay, I think I just like kissing people. I am straight but I'm very open to pretty much anything.”

Most participants explained that their same-sex activities reaffirmed their heterosexuality, but still reserve the right to continue engaging in "experimentation" with their female friends. For example:

"The most important thing in developing my sexual orientation is exposure to both sexes on a sexual level. In previous encounters with women, I've always had something in the back of my head like 'wait...this is kind of weird!' I never think of that when I'm with a man. I would never pursue anything with a female past kissing these days. Sure, relationships have crossed my mind, but that is completely it. I see myself with husband and beautiful children in the future!”

Other participants described that their same-sex experiences generally led them back to a heterosexual orientation, but that they were also open to future changes. For example, one participant explained, "I do not consider myself to be bisexual but I also think that it is not possible to be completely heterosexual. I have kissed other girls drunkenly but I do not think that makes me attracted to women. However, that does not mean I consider myself completely straight.” Another participant described her feelings towards same-sex behaviors: 
"I did question my sexual orientation once. It happened in my junior year of high school. One of my friends was a lesbian and we would hang out often. After some time I believed I started having sexual feelings for her. I think it was more of a curiosity at that time. I wanted to have sex with her but I didn't want to actually have a romantic relationship with her. Other activities that have involved me with women since I entered into college have only included kissing other girls, but I've found that I do not get aroused or turned on by kissing them. I consider myself more attracted to men but I do occasionally fantasize about what it would be like to have sex with a member of the same sex.”

\section{Qualitative Comparison between Heterosexual Questioning and Sexual-Minority Women}

In addition to descriptively exploring heterosexual women's questioning processes, we also conducted a qualitative comparison of heterosexual questioning women's narratives and those provided by our smaller sample of sexualminority women. In particular, we examined HQ and sexual-minority narratives for overlapping and divergent themes.

Similarities between HQ and sexual-minority young women's responses emerged, such that both groups of participants described prompting from the social context as an important part of their questioning process. For example, a woman who identified as "bisexual" explained, "College has definitely been an important part to my sexual orientation. I found on this campus it was okay to be gay or lesbian or bisexual and there is no reason for me to fear what is inside of me." However, sexual-minority participants often described that an accepting social context facilitated "coming-out" and self-acceptance (e.g., "I just know that being exposed to [bisexuality] and feeling like it was okay really helped my sexuality to emerge.”), whereas heterosexual women frequently described the social context as opening the possibility of alternative orientations to heterosexuality.

In addition to prompting from the social context, sexual-minority women also described their questioning processes originating with assessment of same-sex attraction and evaluations of same-sex behaviors. For example, a woman who identified as "bisexual" explained, "I remember first questioning my orientation when I was 13 after I developed my first crush on a girl. After realizing I had a crush on her and [that I] had lesbian tendencies, I wondered whether I liked boys at all and then decided I like both sexes." Another woman who identified as “exclusively gay/lesbian” explained:

"I resisted this questioning for years - my mother has told me that at age 8 she caught me and my female friend Betty kissing and she talked to me about being gay, and I repeatedly yelled 'I'm not a lesbian!!' Finally at the age of 15 I was forced to come to terms with the fact that I am a gay female (I was kissed by a girl and entered a romantic relationship with her), and now I'm totally accepting of it.”

Another woman who identified as “exclusively gay/lesbian” described:

"I remember first questioning if I liked girls when I was about 12. The main reason was that I was never as interested in guys as my friends were. I could have cared less if I had a boyfriend or not. I was also very attracted to my female friends. I think I spent more and more time checking girls out so that was definitely a red flag."

Thus, both HQ and sexual-minority women relayed similar themes regarding processes by which their sexual orientation questioning began. While both groups noted assessing same-sex desires and behaviors as important aspects of their questioning processes, an obvious and important difference that emerged between the HQ and sexual-minority participants' narratives was that these processes resulted in facilitation of a sexual-minority identity for some and reaffirmed a heterosexual identity for others.

\section{Discussion}

A primary goal of this exploratory study was to ascertain the frequency of sexual orientation questioning among heterosexual women. Preliminary analyses revealed that two-thirds of "exclusively straight"-identified women indicated having thought about and/or questioned their sexual orientation, which included the recognition and consideration of alternative sexual orientation identifications. These preliminary findings suggest that among this particular population, heterosexuality may be less invisible, if not still compulsory, than previously understood. 
Additionally, for the 33\% of women who indicated having not questioned their sexual orientation, it is still possible that this population may engage in sexual orientation questioning at a later date. As sexual identity development is a dynamic process that highly salient in young adulthood (Worthington et al., 2002), these participants may be in early stages of sexual identity exploration and may return later in their development to engage in more elaborated exploration and identity shifts (Diamond, 2008b; Chapman \& Brannock, 1987; Savin-Williams, 2005). This point is supported by the finding that the HNQ group was the youngest of the three groups, and significantly younger than the sexual-minority group. Additionally, it is important to recognize that even the HQ women may start new, continue, or revisit previous questioning processes at later points; future questioning may even lead these women to consider and adopt an alternative sexual identity. Though moving away from an "exclusively heterosexual" label would challenge compulsory heterosexuality, alternative identity labels that break down the previously embraced rigid categories may better suit their experiences.

Quantitative analyses revealed that there are ways in which the HQ and HNQ women are similar and arenas in which they differ. The lack of difference in feminine gender ideology and other-sex experience suggests that both HQ and HNQ women have been equally impacted by hegemonic feminine ideals, requiring heterosexual activity to fulfill these prescribed gender roles. The finding that HQ and HNQ women held similarly high levels of sexual identity commitment was counter to our expectations, but suggests that questioning one's orientation does not necessarily result in less commitment to one's sexual identity. HQ women's higher same-sex sexual experience and greater sexual identity uncertainty and exploration and less integration are understandable given these women's current or past history of questioning their orientation and suggest the potential for future movement in their sexual identities. These similarities and differences in sexual identity measures between HQ and HNQ women have been echoed in previous research that showed women of varying sexual identity subtypes (e.g., exclusively straight vs. mostly straight) were equally committed to their sexual identities, despite mostly straight women exhibiting more exploration, uncertainty, and less synthesis/integration (Thompson \& Morgan, 2008).

Also understandable were HQ and HNQ women's divergent responses on measures of LGB knowledge and attitudes, where HQ women were overall more tolerant and knowledgeable than the HNQ women. It is possible that HQ women may have developed more tolerant views towards LGB individuals through greater contact with sexualminority individuals and from having participated in more same-sex activities, coupled with slightly higher levels identity exploration and uncertainty. Conversely, their openness to LGB populations may have contributed to their own same-sex behavioral and identity explorations.

Just as all heterosexual women are not a uniform group, neither are the questioning processes employed by these women. Not only do the results of this study suggest that sexual orientation questioning is fairly common among college women, but the data also reveal several important ways that college women define and describe how they have questioned their sexual orientation. Analyses of HQ women's narratives indicated that sexual identity questioning consists of evaluations of both other-sex and same-sex experiences, and includes important influences from the social context. It is not surprising that some women would rely on their other-sex experiences to guide their understanding of a heterosexual identity, but many women also viewed a dearth of other-sex experiences as a potential indicator that their orientation was possibly not heterosexual. Questioning one's sexual orientation through other-sex behavior does not require actual participation in same-sex activities, either cognitively or behaviorally, and thus may be more socially acceptable than actually testing one's sexual attraction or arousal to women. Nonetheless, though somewhat passive, the act of questioning reflects a willingness to transgress normative (hetero)sexual assumptions and make salient an often invisible identity.

Other participants relied on their social context to prompt questioning, either through introducing them to sexualminority individuals or tolerant communities, or through others' questioning of their own sexual orientation. This finding coincides with previous research that has indicated that sexual-minority women frequently cite sexual attraction to and behavior with same-sex friends as significant influences on their sexual identity development (e.g., Diamond, 2002; Morgan \& Thompson, 2006). Interesting, while the results from this study revealed that the social context facilitated questioning, both Eliason's (1995) and Boratav's (2006) studies included references to "outside forces" like society, family, peers, and the media that encouraged and even mandated their heterosexuality. It is possible the more tolerant historical and social contexts of the present study (e.g., Savin-Williams, 2005; Thompson, 2006, 2009), along with the methodology that included specific inquiries about identity questioning, account for this shift. 
The two other emergent themes represented questioning processes that involved active cognitive or behavioral same-sex exploration. HQ women's descriptions of either assessing same-sex attraction or evaluating same-sex behaviors coincide with the active exploration component of Worthington et al.'s (2002) heterosexual identity development model. Through active exploration, heterosexual and sexual-minority women deviate from ideologically prescribed pathways of sexual exploration to entertain same-sex crushes, fantasies and sexual activities - processes of active questioning that have the potential to challenge the confines of compulsory heterosexuality (Diamond, 2005b). However, despite recognition of sexual attraction towards or romantic interest in women, the HQ participants insisted on maintaining an "exclusively heterosexual" identity, which reifies the confines of compulsory heterosexuality. It is also important to note that the HQ women's same-sex sexual behavioral experiences were often fleeting or conditional, occurring within a liberal social context and under the influence at parties and in the presence of men. Because same-sex sexuality among women has become "trendy" in popular media and peer culture, questioning in heterosexual women due to behavioral experiences could be seen as a less serious questioning process and less transgressive of heteronormativity than it appears. Recent research has theorized about and focused on these behaviors and social spaces as both facilitative and hindering of women's genuine sexual-minority identity development (Diamond, 2005c; Thompson, 2006, 2009).

The qualitative comparison between HQ and sexual-minority women revealed anticipated parallels and divergences and lent further empirical support to Worthington et al.'s (2002) and McCarn and Fassinger's (1996) models of sexual identity development. Questioning processes employed by both heterosexual and sexual-minority individuals included a point at which attraction or orientation was unclear to the individuals. But, while heterosexuallyidentified individuals turned back towards a heterosexual identity at this point, sexual-minority individuals evidenced a turning point in which they recognized an alternative identity and progressively moved towards selfaffirmation and disclosure to others (McCarn \& Fassinger, 1996). As such, the goals of questioning for heterosexual women did not include the construction of a completely new sexual identity but instead the reification of a previously abstract, unexplored sense of identity. Despite these differences, both heterosexual and sexual-minority women were susceptible to cultural constraints in their processes of sexual identity questioning (e.g., compulsory heterosexuality) and risked stigmatization in order to explore, challenge, and substantiate their sexual identities' through questioning experiences.

Lastly, the findings from this study offer a comparison point to a similar study assessing heterosexual men's sexual orientation questioning (Morgan, et al., in press). While about fifty percent of heterosexual men indicated having questioned their sexual orientation, a higher percentage of heterosexual questioning women emerged in the present study, suggesting that perhaps there is greater space for women to explore alternative sexual identities than men as a result of other-sex directed same-sex behaviors (Diamond, 2005c; Thompson, 2006, 2009) that result in the impetuses for questioning among heterosexual women having less to do with "feelings of difference" or transgressive sexual desires (Hammack, Thompson, \& Pilecki, 2009). Furthermore, inductive thematic analyses revealed slightly different processes of questioning for men and women, such that men more frequently offered unelaborated and other-sex experiences as important influences, unlike the women in this study who most often offered same-sex oriented impetuses for questioning. Similarly, both men and women noted the importance of the social context, including exposure to sexual-minority individuals and communities, for prompting sexual orientation questioning.

\section{Limitations and Future Directions}

Despite the compelling nature of these exploratory results, they do not fully speak to the true diversity of experience within heterosexual women's identity development. Studies with participants of different ethnic, geographical, educational, and economic backgrounds could help clarify patterns and nuances in sexual orientation questioning. The participants in this study were college students at a liberal institution, which likely contributed to the potential for questioning. Examining heterosexual identity development among more traditional undergraduate institutions in more regionally conservative areas, as well as non-collegiate young adults, would be necessary for generalization of these results. Additionally, longitudinal studies would help increase our understanding of the identity trajectories of both questioning and non-questioning emerging adults, as the results from this study provide a snapshot of a developmental period in which many individuals are just beginning to explore and adopt alternative sexual identities (Savin-Williams \& Diamond, 2000). The heterosexually-identified women in this study may return to questioning 
their sexual orientation via different processes at a later point in time, with potentially different end results. Furthermore, research should continue to assess heterosexual individuals who have not questioned their orientation in attempts to understand their developmental experiences.

It is apparent that the heterosexual identities of the women in this study are far from uniform. As the HQ women moved into different contextual spaces, they were not only shaped by societal representations of heterosexuality, but also contributed to them in significant ways. For instance, many HQ women viewed the context of college as a venue for engaging in identity-work. Among these HQ women, this context incited a new conceptualization of heterosexuality. HQ participants' beliefs that their heterosexual identities were a desirable end result despite ongoing same-sex attraction and exploration does not detract from the finding that the majority of young heterosexual women in this study were crafting sexual identities cultivated through processes that allowed for the possibility of a sexual-minority identity. Ultimately, the results of this study raise doubts about the current theoretical conceptualization of heterosexuality as a singular, monolithic, universal sexual identity and should prompt researchers to further explore the likely diverse trajectories of female heterosexual identity development. 


\section{References}

Amestoy, M. M. (2001). Research on sexual orientation labels' relationship to behaviors and desires. Journal of Bisexuality, 1(4), 91-113.

Boratav. H. B. (2006). Making sense of heterosexuality: An exploratory study of young heterosexual identities in Turkey. Sex Roles 54, 213-225.

Braun, V., \& Clarke, V. (2006). Using thematic analysis in psychology. Qualitative Research in Psychology, 3, 77101.

Cass, V. C. (1979). Homosexual identity formation: A theoretical model. Journal of Homosexuality, 4, $219-235$.

Cass, V. C. (1984). Homosexual identity: A concept in need of a definition. Journal of Homosexuality, 9, $105-126$.

Chapman, B. E., \& Brannock, J. C. (1987). Proposed model of lesbian identity development: An empirical examination. Journal of Homosexuality, 14, 69-80.

Connell, R. (2006). Understanding men: Gender sociology and the new international research on masculinities. In C. Skelton, B. Francis, \& L. Smulyan (Eds.), The Sage handbook of gender and education (pp. 18-30). Thousand Oaks, CA US: Sage Publications, Inc.

Diamond, L. M. (2002). Having a girlfriend without knowing it: Intimate friendships among adolescent sexualminority women. Journal of Lesbian Studies, 6, 5-16.

Diamond, L. M. (2005a). A new view of lesbian subtypes: Stable versus fluid identity trajectories over an 8-year period. Psychology of Women Quarterly, 29, 119-128.

Diamond, L. M. (2005b). From the heart or the gut? Sexual-minority women's experiences of desire for same-sex and other-sex partners. Feminism \& Psychology, 15(1), 10-14.

Diamond, L. M. (2005c). 'I'm straight, but I kissed a girl': The trouble with American media representations of female-female sexuality. Feminism \& Psychology, 15(1), 104-110.

Diamond, L. M. (2008a). Female bisexuality from adolescence to adulthood: Results from a 10-year longitudinal study. Developmental Psychology, 44, 5-14.

Diamond, L. M. (2008b). Sexual fluidity: Understanding women's love and desire. Cambridge, MA: Harvard University Press.

Eliason, M. J. (1995). Accounts of sexual identity formation in heterosexual students. Sex Roles, 32, 821-834.

Fassinger, R. E. (2000). Gender and sexuality in human development: Implications for prevention and advocacy in counseling psychology. In S. D. Brown and R. W. Lent (Eds.) Handbook of Counseling Psychology (pp. 346-378). Hoboken, NJ: John Wiley \& Sons.

Fassinger, R. E., \& Miller, B. A. (1996). Validation of an inclusive model of sexual minority identity formation on a sample of gay men. Journal of Homosexuality, 32, 53-78.

Hammack, P. L., Thompson, E. M., \& Pilecki, A. (2009). Configurations of identity among sexual minority youth: Context, desire, and narrative. Journal of Youth and Adolescence, 38, 867-883.

Herdt, G. (1992). “Coming out” as a rite of passage: A Chicago study. In G. Herdt (Ed.) Gay culture in America: Essays from the field (pp. 29-67). Boston: Beacon Press.

Hirschman, C., Impett, E., \& Schooler, D. (2006). Dis/embodied voices: What late-adolescent girls can teach us about objectification and sexuality. Sexuality Research \& Social Policy, 3, 8-20.

Hostetler, A. J., \& Herdt, G. H. (1998). Culture, sexual lifeways, and developmental subjectivities: Rethinking sexual taxonomies. Social Research, 65, 249-290.

Hughes, T. L., Johnson, T., \& Wilsnack, S. C. (2001). Sexual assault and alcohol abuse: A comparison of lesbians and heterosexual women. Journal of Substance Abuse, 13, 515-532.

Impett, E., Schooler, D., \& Tolman, D. (2006). To be seen and not heard: Femininity ideology and adolescent girls' sexual health. Archives of Sexual Behavior, 35, 131-144.

Jackson, S. (2005). 'Dear girlfriend . . .': Constructions of sexual health problems and sexual identities in letters to a teenage magazine. Sexualities, 8, 282-305.

Jackson, S., \& Cram, F. (2003). Disrupting the sexual double standard: Young women's talk about heterosexuality. British Journal of Social Psychology, 42, 113-127.

Kim, J. L., Sorsoli, C. L., Collins K., Zylbergold, B. A., Schooler, D., \& Tolman, D. L. (2007). From sex to sexuality: Explosing the heterosexual script on primetime network television. Journal of Sex Research, 44, 145-157.

Kinnish, K. K., Strassberg, D. S., \& Turner, C. W. (2005). Sex differences in the flexibility of sexual orientation: A multidimensional retrospective assessment. Archives of Sexual Behavior, 34, 173-183.

Kitzinger, C., \& Wilkinson, S. (1993). Theorizing heterosexuality. In S. Wilkinson \& C. Kitzinger (Eds.), Heterosexuality: A feminism \& psychology reader (pp. 1-32). London: Sage. 
Kitzinger, C., \& Wilkinson, S. (1995). Transitions from heterosexuality to lesbianism. Developmental Psychology, 31, 95-104.

Konik, J. \& Stewart, A. (2004). Sexual identity development in the context of compulsory heterosexuality. Journal of Personality, 72, 815-844.

Lambert, T. A., Kahn, A. S., \& Apple, K. J. (2003). Pluralistic ignorance and hooking up. Journal of Sex Research, 40, 129-133.

Long, S., Ullman, S. E., Long, L. M., Mason, G. E., \& Starzynski, L. L. (2007). Women’s experiences of maleperpetrated sexual assault by sexual orientation. Violence and Victims, 22, 684-701.

Marcia, J. E. (1966). Development and validation of ego-identity status. Journal of Personality and Social Psychology, 3, 551-558.

McCarn, S., \& Fassinger, R. (1996). Revisioning sexual minority identity formation: A new model of lesbian identity and its implications. Counseling Psychologist, 24, 508-534.

Morgan, E. M., Steiner, M. G., \& Thompson, E. M. (in press). Processes of sexual orientation questioning among heterosexual men: Cognitive and behavioral exploration. Men \& Masculinities. July 25, 2008: DOI: $10.1177 / 1097184$ X08322632.

Morgan, E. M., \& Thompson, E. M. (2006). Young women’s sexual experiences within same-sex friendships: Discovering and defining bisexual and bi-curious identity. Journal of Bisexuality, 6 (3), 7-34.

Morgan, E. M., \& Zurbriggen, E. L. (2007). Wanting sex and wanting to wait: Young adults' accounts of sexual messages from first significant dating partners. Feminism \& Psychology, 17, 515-541.

Reddy, S., \& Dunne, M. (2007). Risking it: Young heterosexual femininities in South African context of HIV/AIDS. Sexualities, 10, 159-172.

Remafedi, G., Resnick, M., Blum, R., \& Harris, L. (1992). Demography of sexual orientation in adolescents. Pediatrics, 89, 714-721.

Roberts, T. A., Auinger, P., \& Klein, J. D. (2006). Predictors of partner abuse in a nationally representative sample of adolescents involved in heterosexual dating relationships. Violence and Victims, 21, 81-89.

Rich, A. (1980). Compulsory heterosexuality and lesbian existence. Signs, 5: 631-660.

Savin-Williams, R. C. (1995). Lesbian, gay male, and bisexual adolescents. In A. R. D’Augelli \& C. J. Patterson (Eds.), Lesbian, gay, and bisexual identities over the lifespan: Psychological perspectives (pp. 165-189). New York: Oxford University Press.

Savin-Williams, R. C. (2005). The new gay teenager. Cambridge, MA: Harvard University Press.

Savin-Williams, R. C., \& Diamond. L. M. (2000). Sexual identity trajectories among sexual-minority youths: Gender comparisons. Archives of Sexual Behavior, 29, 607-627.

Striepe, M., \& Tolman, D. (2003). Mom, Dad, I'm straight: The coming out of gender ideologies in adolescent sexual-identity development. Journal of Clinical Child and Adolescent Psychology, 32, 523-530.

Thompson, E. M. (2006). Girl friend or girlfriend: Same-sex friendship and bisexual images as a context for flexible sexual identity among young women. Journal of Bisexuality, 6(3), 47-67.

Thompson, E. M. (2009). Young women's same-sex experiences under the "male gaze": Listening for both objectification and sexual agency. Unpublished doctoral dissertation, University of California, Santa Cruz.

Thompson, E. M., \& Morgan, E. M. (2008). "Mostly straight” young women: Variations in sexual behavior and identity development. Developmental Psychology, 44, 15-21.

Tolman, D. L. (2006). In a different position: Conceptualizing female adolescent sexuality development within compulsory heterosexuality. In L. M. Diamond (Ed.), Rethinking positive adolescent female sexual development (pp. 71-89). San Francisco, CA: Jossey-Bass.

Tolman, D., \& Porche, M. (2000). The adolescent femininity ideology scale: development and validation of a new measure for girls. Psychology of Women Quarterly, 24, 365-376.

Troiden, R. R. (1989). The formation of homosexual identities. Journal of Homosexuality, 17, 43-73.

Worthington, R. L., Dillon, F. R., \& Becker-Schutte, A. M. (2005). Development, reliability, and validity of the Lesbian, Gay, and Bisexual Knowledge and Attitudes Scale for Heterosexuals (LGB-KASH). Journal of Counseling Psychology, 52, 104-118.

Worthington, R. L., Navarro, R. L., Savoy, H. B., \& Hampton, D. (2008). Development, reliability and validity of the Measure of Sexual Identity Exploration and Commitment (MoSIEC). Developmental Psychology, 44, 22-33.

Worthington, R. L., Savoy, H. B., Dillon, F. R., \& Vernaglia, E. R. (2002). Heterosexual identity development: A multidimensional model of individual and social identity. Counseling Psychologist, 30, 496-531. 